\title{
Role of Nitric Oxide in Classical Conditioning of Siphon Withdrawal in Aplysia
}

\author{
Igor Antonov, ${ }^{1}$ Thomas Ha, ${ }^{3}$ Irina Antonova, ${ }^{1}$ Leonid L. Moroz, ${ }^{3,4}$ and Robert D. Hawkins ${ }^{1,2}$ \\ ${ }^{1}$ Center for Neurobiology and Behavior, Columbia University, ${ }^{2}$ New York State Psychiatric Institute, New York, New York $10032,{ }^{3}$ The Whitney Laboratory \\ for Marine Bioscience, University of Florida, St. Augustine, Florida 32080, and ${ }^{4}$ Department of Neuroscience and McKnight Brain Institute, University of \\ Florida, Gainesville, Florida 32611
}

\begin{abstract}
Nitric oxide (NO) is thought to be involved in several forms of learning in vivo and synaptic plasticity in vitro, but very little is known about the role of NO during physiological forms of plasticity that occur during learning. We addressed that question in a simplified preparation of the Aplysia siphon-withdrawal reflex. We first used in situ hybridization to show that the identified L29 facilitator neurons express NO synthase. Furthermore, exogenous NO produced facilitation of sensory-motor neuron EPSPs, and an inhibitor of NO synthase or an NO scavenger blocked behavioral conditioning. Application of the scavenger to the ganglion or injection into a sensory neuron blocked facilitation of the EPSP and changes in the sensory-neuron membrane properties during conditioning. Injection of the scavenger into the motor neuron reduced facilitation without affecting sensory neuron membrane properties, and injection of an inhibitor of NO synthase had no effect. Postsynaptic injection of an inhibitor of exocytosis had effects similar to injection of the scavenger. However, changes in the shape of the EPSP during conditioning were not consistent with postsynaptic AMPA-like receptor insertion but were mimicked by presynaptic spike broadening. These results suggest that NO makes an important contribution during conditioning and acts directly in both the sensory and motor neurons to affect different processes of facilitation at the synapses between them. In addition, they suggest that NO does not come from either the sensory or motor neurons but rather comes from another source, perhaps the L29 interneurons.
\end{abstract}

Key words: nitric oxide; classical conditioning; Aplysia; facilitation; sensory neuron; motor neuron

\section{Introduction}

The ubiquitous messenger molecule nitric oxide (NO) can play a variety of roles during artificial forms of synaptic plasticity that are thought to contribute to learning, including acting as a retrograde messenger during long-term potentiation (LTP) in hippocampal neurons and as an orthograde or paracrine messenger during long-term depression in cerebellar neurons (for review, see Hawkins et al., 1998; Hawkins, 2007). NO is also involved in several forms of learning in different species (Hawkins, 1996), including conditioning of feeding behavior in Aplysia (Katzoff et al., 2002). However, very little is known about the role of NO during physiological forms of synaptic plasticity that occur during behavioral learning. We addressed that question in a simplified preparation of the Aplysia siphon-withdrawal reflex in which it is possible to record the activity of individual identified neurons and their synaptic connections during several simple forms of

Received May 23, 2007; revised Aug. 24, 2007; accepted Aug. 27, 2007.

This work was supported by National Institutes of Health Grants MH26212 and P50 HG002806, the Gatsby Initiative in Brain Circuitry, the McKnight Brain Research Foundation, and the University of Florida Opportunity Funds. We thank Eric Kandel, Michael Rogan, and Steven Siegelbaum for their comments on a previous draft of this manuscript.

Correspondence should be addressed to either of the following: Robert D. Hawkins, Center for Neurobiology and Behavior, Columbia University, 1051 Riverside Drive, New York, NY 10032, E-mail: rdh1@columbia.edu; or Leonid L. Moroz, The Whitney Laboratory for Marine Bioscience, University of Florida, 9505 Ocean Shore Boulevard, St. Augustine, FL 32080, E-mail: moroz@whitney.ufl.edu.

DOI:10.1523/JNEUROSCI.2357-07.2007

Copyright $\odot 2007$ Society for Neuroscience 0270-6474/07/2710993-10\$15.00/0 learning, including classical conditioning (Antonov et al., 1999, 2001, 2003).

Previous studies have found that the reflex in the siphonwithdrawal preparation is mediated in part by monosynaptic connections from LE siphon sensory neurons to LFS siphon motor neurons in the abdominal ganglion (Antonov et al., 1999). Conditioning is accompanied by pairing-specific facilitation of the EPSP from an LE sensory neuron to an LFS motor neuron, as well as increased evoked firing and membrane resistance of the LE neuron (Antonov et al., 2001). All three cellular effects are blocked by injecting a peptide inhibitor of protein kinase A (PKA) into the sensory neuron (Antonov et al., 2003), consistent with the idea that facilitation of the EPSP during conditioning involves activity-dependent enhancement of the presynaptic PKA pathway (Hawkins et al., 1983; Kandel et al., 1983; Walters and Byrne, 1983; Ocorr et al., 1985; Eliot et al., 1994; Bao et al., 1998; Abrams et al., 1998). All three effects are also blocked by injecting the $\mathrm{Ca}^{2+}$ chelator BAPTA into the motor neuron (Antonov et al., 2003), consistent with the idea that facilitation of the EPSP involves Hebbian LTP as well (Lin and Glanzman, 1994a,b; Murphy and Glanzman, 1996, 1997, 1999). These results suggest that the facilitation involves both presynaptic and postsynaptic mechanisms coordinated by extracellular signaling.

We have now investigated the possible role of the extracellular signaling molecule NO. First, we used in situ hybridization to show that identified L29 facilitatory interneurons express nitric oxide synthase (NOS), and we found that exogenous NO pro- 
duces facilitation of sensory-motor neuron EPSPs. Next, we investigated the possible role of $\mathrm{NO}$ in facilitation during behavioral conditioning in the siphon-withdrawal preparation. Our physiological results suggest that NO makes an important contribution to the conditioning and facilitation and acts directly in both the sensory and motor neurons to affect different processes of facilitation at the synapses between them. In addition, those results suggest that NO does not come from either the sensory or motor neurons but rather comes from another source (perhaps the L29 interneurons), consistent with the in situ hybridization results.

\section{Materials and Methods}

The procedure for NADPH-diaphorase staining in Aplysia and related gastropod mollusks has been described previously (Moroz, 2000, 2006). The methods for probe preparation and in situ hybridization as well as Lucifer yellow double labeling have also been described previously (Jezzini et al., 2005). Briefly, in situ riboprobes were prepared using cloned full-length NOS cDNA from Aplysia californica (AcNOS-1; GenBank accession number AAK83069) (Sadreyev et al., 2000) (for details of the molecular data and the relationships between different NOS isoforms in mollusks, see Moroz et al., 2006; Moroz and Kohn, 2007). NOS antisense and the control sense probes were generated by using the DIG RNA Labeling kit (Roche Diagnostics, Indianapolis, IN). The antisense probe was generated by digesting cDNA from AcNOS-1 with NotI (New England Biolabs, Beverly, MA) followed by transcription with T3 polymerase from the DIG RNA Labeling kit (Roche Diagnostics). The control sense probe was produced by the same protocol but used Pmel (New England Biolabs) to digest the cDNA and T7 polymerase for transcription. Expression of AcNOS-1 was investigated in whole mounts of abdominal ganglia from 16 experimental and five control preparations. Control in situ hybridization experiments with full-length sense probes did not reveal any selective staining of specific neurons in the CNS under identical conditions and labeling protocols.

The behavioral and electrophysiological procedures have been described previously (Antonov et al., 2003). Briefly, the siphon, tail, and CNS of Aplysia californica were dissected and pinned to the floor of a recording chamber filled with circulating, aerated artificial seawater (ASW) at room temperature (see Fig. 3B1). The siphon was partially split, and one-half was left unpinned. A controlled force stimulator was used to deliver taps of $\sim 20 \mathrm{~g} / \mathrm{mm}^{2}, 500 \mathrm{~ms}$ duration to the pinned half, and withdrawal of the other half was recorded with a low-mass isotonic movement transducer attached to the siphon with a silk suture. The peak amplitude of withdrawal was measured using a laboratory interface to a microcomputer and commercially available software, which also controlled the stimulation. A fixed capillary electrode was used to deliver alternating current electric shocks of $25 \mathrm{~mA}, 1 \mathrm{~s}$ duration to the tail.

The preparation was rested for at least $1 \mathrm{~h}$ before the beginning of training. There were three blocks of four training trials each, with a $5 \mathrm{~min}$ interval between trials in a block and a 20 min rest between blocks (see Fig. 3B2). The response to the siphon tap conditioned stimulus (CS) was measured in a pretest $5 \mathrm{~min}$ before the first block (Pre), in test trials 15 min after each block (T1-T3), and in a final posttest 45 min after the last block (Post). During paired training, the CS began $0.5 \mathrm{~s}$ before the tailshock unconditioned stimulus (US) on each trial. During unpaired training, the interstimulus interval was $2.5 \mathrm{~min}$. Animals were randomly assigned to the training conditions.

In pharmacological experiments, the abdominal ganglion was surrounded by a circular well with the nerves led through a Vaseline seal, so that the ganglion could be bathed in a different solution than the rest of the preparation. In electrophysiological experiments, the abdominal ganglion was partially desheathed, and an LE sensory neuron and LFS motor neuron were impaled with double-barreled microelectrodes. On each test trial, we measured siphon withdrawal, evoked firing of the LE and LFS neuron, the membrane resistance of each neuron, and the monosynaptic PSP produced in the LFS neuron by direct stimulation of the LE neuron. In some experiments, we injected drugs into the LE or LFS neuron from the second barrel of the electrode. In interleaved control experiments, we injected vehicle.

The NO donor 2-( $N, N$-diethylamino)-diazenolate-2-oxide (DEA/ NO) (Alexis Biochemicals, San Diego, CA) was dissolved in $10 \mathrm{~mm}$ $\mathrm{NaOH}$ and diluted in ASW immediately before use. $N^{\omega}$-Nitro-Larginine, 4-aminopyridine (4-AP), APV, and CNQX (Sigma, St. Louis, $\mathrm{MO})$ were prepared as stock solutions in water and diluted in ASW. KT5823 [(9S,10 R,12R)-2,3,9,10,11,12-hexahydro-10-methoxy-2,9dimethyl-1-oxo-9,12-epoxy-1 $H$-diindolo[1,2,3-fg:3', $2^{\prime}, 1^{\prime}$-kl]pyrrolo[3,4-i][1,6]benzodiazocine-10-carboxylic acid methyl ester] (Calbiochem, La Jolla, CA) was prepared in DMSO and diluted to a final concentration of $0.1 \%$ DMSO. The light chain of botulinum toxin type $\mathrm{B}$ (List Biological, Campbell, CA) was prepared in $20 \mathrm{~mm} \mathrm{NaH}_{2} \mathrm{PO}_{4}, \mathrm{pH}$ $6.0,10 \mathrm{~mm} \mathrm{NaCl}$, and $5 \mathrm{~mm}$ dithiothreitol and diluted approximately fivefold in electrode solution with $\mathrm{KCl}$ and fast green. Oxymyoglobin was prepared as described by Lev-Ram et al. (1995). The data were analyzed with two- or three-way ANOVAs with one repeated measure (test), followed by planned comparisons of the difference between the experimental and control groups and the reduction of that difference by each drug (the drug $\times$ treatment interaction) overall, and then at each test to define the time courses of those effects (Winer et al., 1991). The experiments shown in Figures $4-8$ were interleaved and analyzed statistically as a single design.

\section{Results}

\section{Aplysia NOS is expressed in L29 facilitatory interneurons}

If NO is involved in conditioning, there should be an appropriate source of the molecule. We therefore searched for NOS containing neurons in the abdominal ganglion. Previous studies using NADPH-diaphorase histochemistry as a putative marker for NOS on cryostat sections indicated that there are a few neurons and numerous processes in the ganglion that could be sources of NO (Koh and Jacklet, 2001). To facilitate locating NOS containing neurons in vivo, we performed similar experiments on wholemount preparations of central ganglia (Moroz, 2006) and observed three neurons on the left ventral surface of the abdominal ganglion that could be NO-producing cells (Fig. $1 \mathrm{~A}$ ). These cells were observed in the general area of the L29 facilitatory interneurons, but they might also have been LE sensory neurons, LFS motor neurons, or other interneurons such as the L30 cells, all of which are found in neighboring areas (Fig. $1 B$ ). In addition, NADPH-diaphorase histochemistry is not completely specific for NOS. To examine more definitively whether any of these cell types are NOS containing, we therefore first positively identified them based on their size, position, synaptic connections, and other electrophysiological properties (Byrne et al., 1974; Hawkins et al., 1981a; Frost and Kandel, 1995) in semi-intact preparations (Fig. 1C) and injected the identified cells with Lucifer yellow dye using hyperpolarizing current. We then tested whether the identified neurons labeled for NOS by whole-mount in situ hybridization, using a specific probe for the recently cloned Aplysia neuronal isoform (GenBank accession number AAK83069) (Moroz et al., 2006) (Figs. 1D, 2A). These experiments revealed that LE sensory neurons $(n=5)$, LFS motor neurons $(n=5)$, and L30 interneurons $(n=4)$ are not NOS containing. In contrast, some of the L29 neurons were NOS positive $(n=7)$. At least two L29 neurons in each preparation could be NOS containing. Surprisingly, however, there were also NOS-negative L29 neurons $(n=3)$ in the same preparation as the NOS-positive L29 neurons (Fig. 2A). In those cases, the NOS-positive and NOS-negative neurons were functionally electrically coupled (Fig. 2 B). In situ hybridization experiments with a second Aplysia NOS isoform (GenBank accession number AAK92211) or a nonconventional NOS-like protein from Aplysia (Moroz and Kohn, 2007) did not reveal any neuron-specific labeling in the abdominal ganglion 

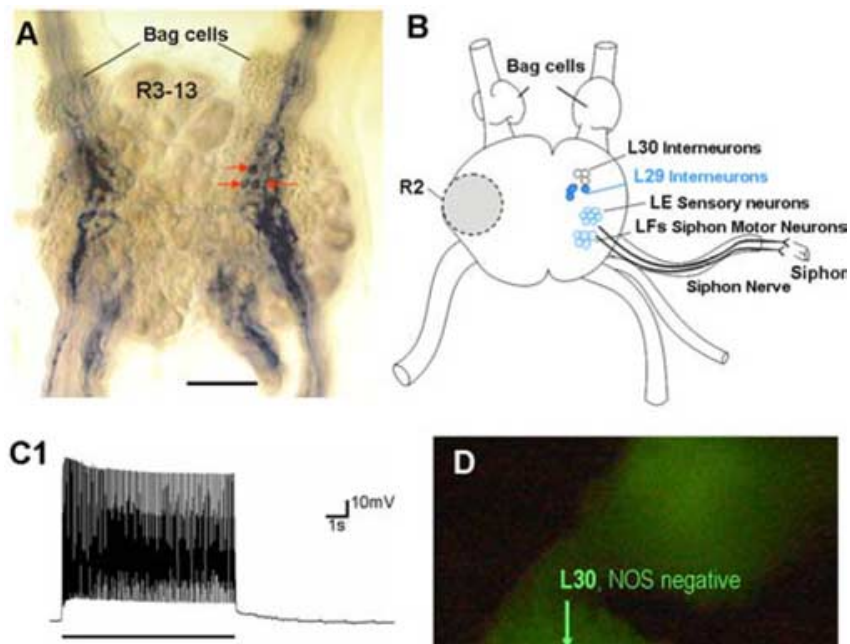

C2
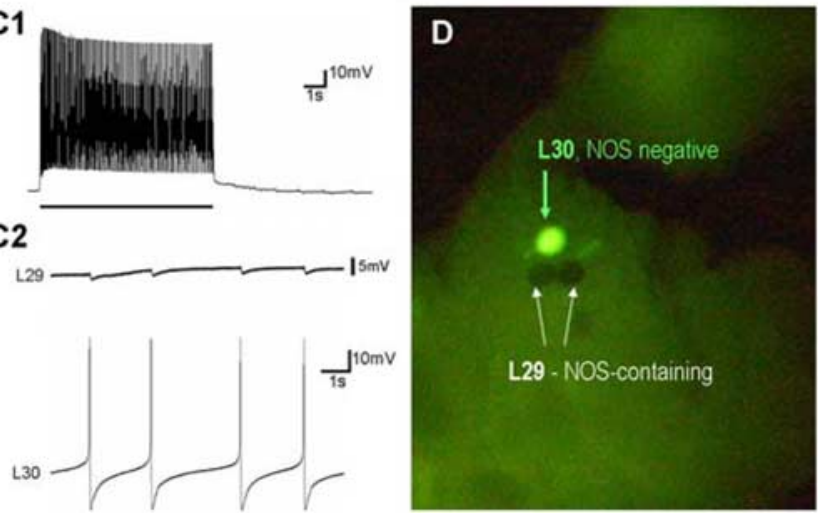

Figure 1. L29 facilitatory interneurons express NO synthase. A, NADPH-diaphorase histochemistry labeled three neurons on the left ventral surface of the abdominal ganglion and numerous processes in the neuropil (for details, see Moroz, 2006). R3-R13 and the bag cell clusters are indicated for orientation. Scale bar, $280 \mu \mathrm{m}$. B, Approximate locations of the L29 and $\mathrm{L} 30$ interneurons, LE sensory neurons, and LFs motor neurons. The siphon nerve and R2 are indicated for orientation. C, Intracellular stimulation of an L29 interneuron recruits a characteristic shower of IPSPs onto itself (C1) attributable to recurrent inhibition from the L30 interneurons (C2). D, Double labeling with intracellular injection of Lucifer yellow and in situ hybridization for Aplysia NOS revealed two NOS-positive L29 interneurons and an NOS-negative L30 interneuron in the same preparation. Intense labeling of the NOS-positive neurons partially masked the Lucifer yellow fluorescence, which was more clearly visible at earlier stages of the NOS staining protocol or at higher magnification.

(Bodnarova et al., 2002; Martasek et al., 2002, 2004) (L. Moroz, M. Bodnarova, A. Kohn, and Y. Bobkova, unpublished observations), suggesting that the NOS-negative neurons do not express other NOS-related isoforms. These results indicate that a subgroup of L29 facilitatory interneurons express one isoform of Aplysia NOS and therefore could be a source of NO.

\section{Exogenous NO produces facilitation}

We next examined whether exogenous NO can produce facilitation of the EPSP from an LE sensory neuron to an LFS motor neuron. Application of the NO donor DEA/NO $(10 \mu \mathrm{M})$ to the abdominal ganglion for $10 \mathrm{~min}$ produced an increase in the amplitude of the EPSP $\left(X=155 \%\right.$ of pretest; $F_{(1,80)}=23.22 ; p<$ 0.01 compared with saline control) with no significant effect on the membrane resistance of the LE or LFS neuron (Fig. 3A). These results suggest that $\mathrm{NO}$ is a facilitatory messenger at these synapses. Injection of the membrane-impermeant NO scavenger oxymyoglobin ( $2 \mathrm{~mm}$ in the electrode) into the sensory neuron blocked the facilitation $(F=45.04 ; p<0.01)$, whereas injection of oxymyoglobin into the motor neuron had no significant effect. These results suggest that NO acts directly in the sensory neuron during the facilitation.

\section{An inhibitor of NO synthase blocks conditioning}

We then examined whether an inhibitor of NO synthase can block conditioning in the siphon-withdrawal preparation. We
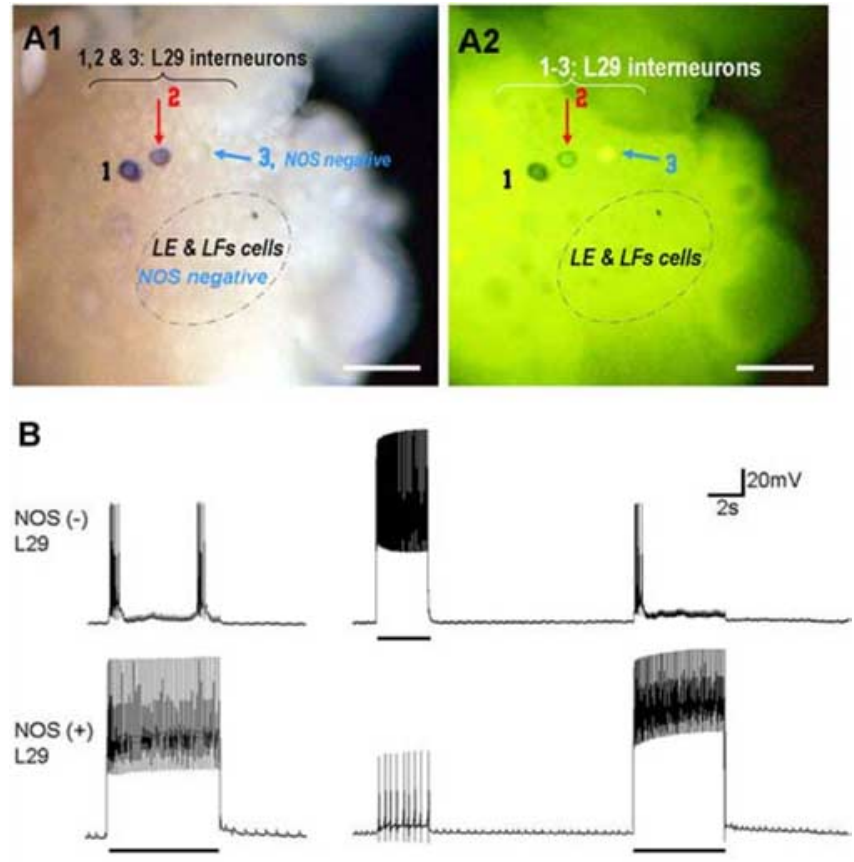

Figure 2. A subset of L29s are NOS negative. A, Double labeling with in situ hybridization for Aplysia NOS (A1) and intracellular injection of Lucifer yellow (A2) revealed that at least two L29s (indicated by 1 and 2) in the same ganglion are NOS positive, but others (e.g., 3) are NOS negative. LE sensory neurons and LFs motor neurons were all NOS negative. Scale bar, $110 \mu \mathrm{m}$. $\boldsymbol{B}$, NOS-positive and NOS-negative L29 interneurons were functionally electrically coupled.

compared changes in the withdrawal reflex in groups that received either paired or unpaired training with a siphon tap CS and a tail-shock US while the abdominal ganglion was bathed in either normal seawater (control) or the NO synthase inhibitor $N^{\omega}$-nitro-L-arginine (Fig. $3 B$, NOArg). This class of competitive NOS inhibitors has been shown to suppress selectively enzymatic $\mathrm{NO}$ production in both vertebrate and invertebrate preparations, including molluscs (Moroz et al., 1996, 2005; Bodnarova et al., 2005). In the control group, paired training produced an increase in the response to the CS compared with either the pretest or unpaired training $\left(F_{(1,138)}=11.46 ; p<0.001\right.$ for the effect of pairing overall and $p<0.05$ at each test), demonstrating classical conditioning of the siphon-withdrawal reflex in the simplified preparation. $N^{\omega}$-nitro-L-arginine $(500 \mu \mathrm{M})$ blocked conditioning $(F=7.80 ; p<0.01$ for the interaction of drug and pairing overall and on the posttest), suggesting that NO is involved. Because NO is thought to act by stimulating cGMP and cGMPdependent protein kinase (PKG) in many systems, including Aplysia neurons (Mothet et al., 1996a; Koh and Jacklet, 1999, 2001; Sung et al., 2004; Bodnarova et al., 2005), we tested an inhibitor of PKG, KT5823 (2 $\mu \mathrm{M})$, which also blocked conditioning $(F=8.32 ; p<0.01$ overall and on the posttest). Neither drug had significant effects on the amplitude of the initial response to the CS or US. These results suggest that the NO-cGMP-PKG pathway contributes to conditioning of the withdrawal reflex.

\section{Neural correlates of conditioning in LE sensory neurons and LFS motor neurons}

Although $N^{\omega}$-nitro-L-arginine and KT5823 were restricted to the abdominal ganglion in these experiments, they might have acted at sites other than the LE sensory neurons and LFS motor neurons. To analyze the possible site of action of NO in more detail, we recorded intracellularly from an identified LFS siphon motor 
neuron and an LE siphon sensory neuron simultaneously with behavioral conditioning. In each experiment, we first confirmed that both neurons contributed to the behavior: the LE sensory neuron was activated by the siphon tap CS, and stimulation of the LFS motor neuron produced measurable siphon withdrawal. In control experiments (Fig. 4), paired training produced greater increases than unpaired training in siphon withdrawal in response to the CS $\left(F_{(1,74)}=45.36 ; p<\right.$ 0.001 overall and $p<0.01$ at each test), evoked LFS firing $(F=51.74 ; p<0.001)$, evoked LE firing $(F=27.00 ; p<0.001)$, the amplitude of the monosynaptic EPSP from the LE sensory neuron to the LFS motor neuron $(F=57.01 ; p<0.001)$, and the membrane resistance of the LE sensory neuron $(F=31.09$; $p<0.001)$. Furthermore, there were significant within-group correlations between the increases in these measures $(p<0.05$ for each pairwise comparison except siphon withdrawal and LE membrane resistance), and there was no change in the membrane resistance of the LFS neuron. These results replicate those of our previous studies (Antonov et al., 2001, 2003) and suggest that pairingspecific increases in the monosynaptic sensory neuron-motor neuron EPSPs make an important contribution to the increase in siphon withdrawal during conditioning. In addition, they demonstrate pairing-specific changes in the membrane properties of the LE sensory neurons that may contribute to the changes in the EPSP and siphon withdrawal.

\section{A scavenger of NO blocks behavioral conditioning, facilitation of the EPSP, and the changes in sensory neuron membrane properties}

If NO contributes to these cellular effects and comes from some other source such as the L29 neurons, it should travel through the extracellular space. To test that idea, we performed similar experiments while bathing the abdominal ganglion with a membrane-impermeable scavenger of NO, oxymyoglobin (Fig. 5). Oxymyoglobin ( $25 \mu \mathrm{M})$ reduced the pairing-specific increases in siphon withdrawal $\left(F_{(1,296)}=7.14 ; p<0.01\right.$ for the interaction of drug and pairing on the posttest), evoked LFS firing $(F=10.54 ; p<0.01)$, evoked LE firing $(F=4.89 ; p<0.05)$, the amplitude of the monosynaptic $\operatorname{EPSP}(F=6.26 ; p<0.05)$, and the membrane resistance of the LE sensory neuron $(F=3.96 ; p<0.05$ overall). The effect of oxymyoglobin on siphon withdrawal was reduced when the correlations with either evoked LE firing or the amplitude of the monosynaptic EPSP were factored out in analyses of covariance, suggesting that $\mathrm{NO}$ affects behavioral conditioning by affecting those two cellular processes. As controls, oxymyoglobin had no significant effect on the membrane resistance of the LFS motor neuron, the initial siphon withdrawal to the tail-shock US or the pretest response on any measure. These results are all consistent

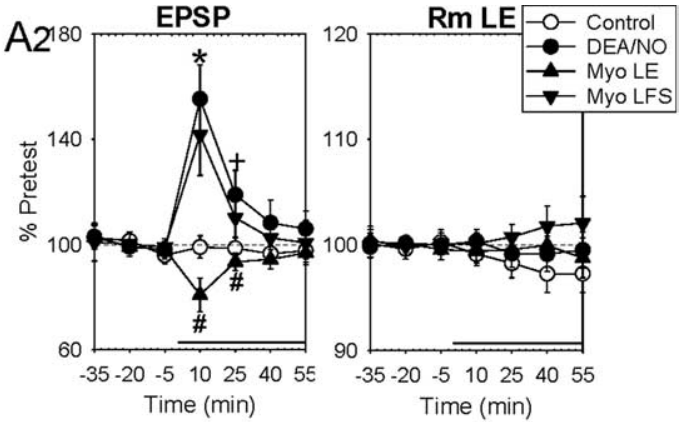

B2

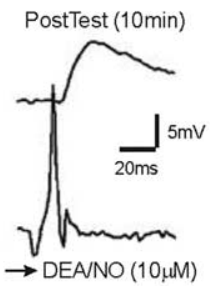

Time (min)

Time (min)
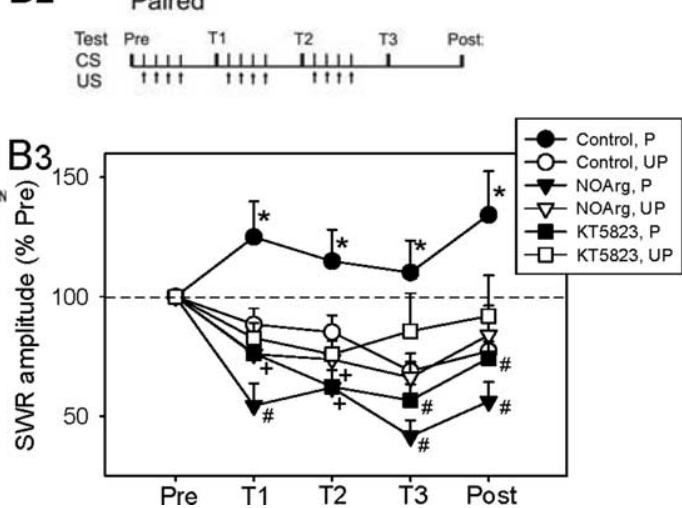

Figure 3. NO is involved in facilitation and conditioning. $\boldsymbol{A}$, Application of the NO donor DEA/NO produces facilitation of the monosynaptic EPSP from an LE sensory neuron to an LFS motor neuron by a direct action in the sensory neuron. $\boldsymbol{A}$ 1, Example of the (Pretest) and 10 min after (Posttest) application of DEA/NO (10 $\mu \mathrm{m})$ to the abdominal ganglion. A2, Average results which DEA/NO was applied after injection of the NO scavenger oxymyoglobin into either the sensory $(n=6)$ or motor $(n=6)$ MN, motorneuron B2 Training protocol. For details, see Materials and Methods. B3 Average siphon-withdrawal reflex (SWR) on test in groups that received paired (P) or unpaired (UP) training with the abdominal ganglion bathed in either normal KT5823 ( $n=21$ and 21). There was a significant overall drug $\times$ pairing interaction $\left(F_{(2,138)}=6.06 ; p<0.01\right)$ experimental groups in one-way ANOVAs. In this and subsequent figures, error bars indicate SEMs. ${ }^{*} p<0.05,{ }^{+} p<0.05$, one-tailed for the difference between the experimental and control groups, and ${ }^{\#} p<0.05,{ }^{+} p<0.05$, one-tailed for the reduction of that effect by the drug at each test.

with the idea that NO acts as an extracellular messenger at the LE-LFS synapses during conditioning. Oxymyoglobin reduced evoked firing of the LE sensory neuron during unpaired as well as paired training $\left(F_{(1,36)}=4.55 ; p<0.05\right)$. Because changes in the membrane resistance and evoked firing of the LE neurons are thought to be mediated primarily by PKA (Byrne and Kandel, 1996; Antonov et al., 2003), these results suggest that NO may interact in some way with the presynaptic PKA pathway.

Injecting a scavenger of NO into a sensory neuron blocks facilitation and the changes in sensory neuron membrane properties

To examine whether NO acts directly in the sensory or motor neuron, we injected oxymyoglobin into either neuron. Injecting oxymyoglobin ( $2 \mathrm{~mm}$ in the electrode) into a single LE sensory neuron (Fig. 6) did not have significant effects on either siphon withdrawal or evoked LFS firing, presumably because the withdrawal response in this preparation is mediated by five to eight LE 
A
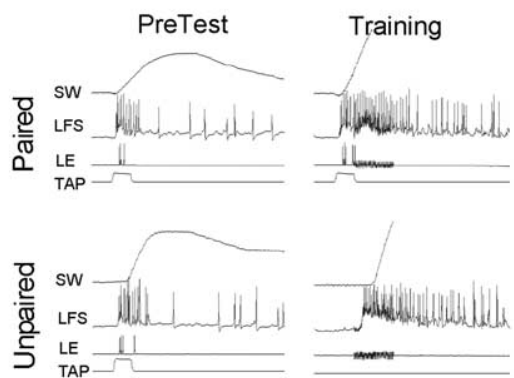

Control

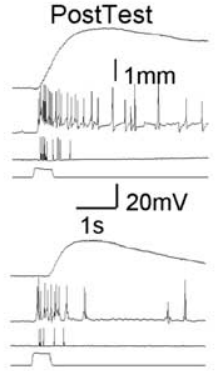

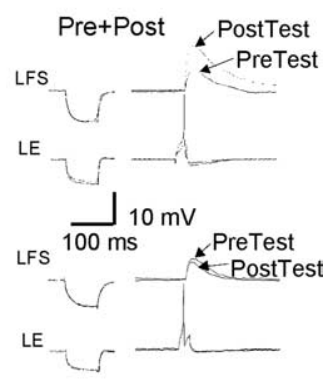

EPSP

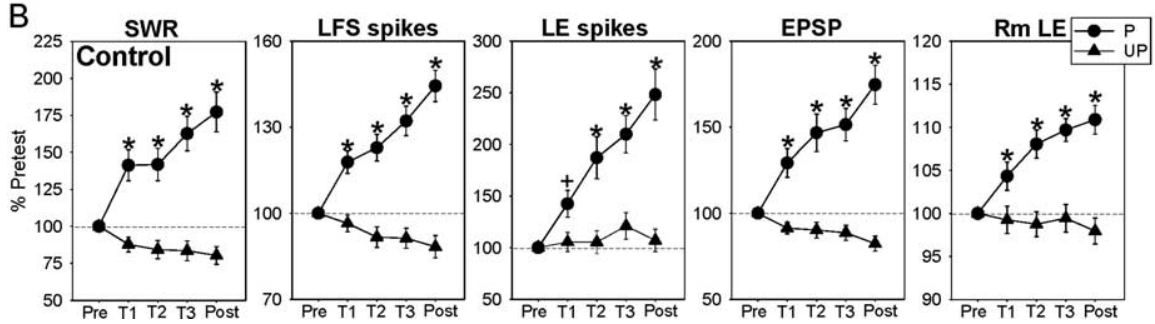

Figure 4. Neural correlates of conditioning in LE sensory neurons and LFS motor neurons. $\boldsymbol{A}$, Examples of siphon withdrawal (SW), evoked firing of an LFS siphon motor neuron and an LE siphon sensory neuron, the membrane resistance of each neuron, and the monosynaptic EPSP from the LE neuron to the LFS neuron on the pretest and final posttest after paired or unpaired training with the abdominal ganglion bathed in normal seawater. $\boldsymbol{B}$, Average results from experiments like the ones shown in $\boldsymbol{A}[n=20$ paired (P) and 20 unpaired (UP)]. Results from four different control groups (bathing the abdominal ganglion in normal seawater or inactive myoglobin, or injecting vehicle into an LE sensory neuron or heatinactivated botulinum toxin into an LFS motor neuron; $n=5$ paired and 5 unpaired per group) were not significantly different on any measure and have been pooled. The data have been normalized to the value on the pretest in each experiment. The overall average pretest values in the experiments shown in Figures $4-8$ were $1.8 \mathrm{~mm}$ for siphon withdrawal, 14.1 spikes for evoked LFS firing, 3.4 spikes for evoked LE firing, and $6.6 \mathrm{mV}$ for the amplitude of the EPSP. The average response to the first tail-shock US was $4.3 \mathrm{~mm}$. These values were not significantly different between the different experimental groups. SWR, Siphon-withdrawal reflex; Rm LE, LE membrane resistance.

A

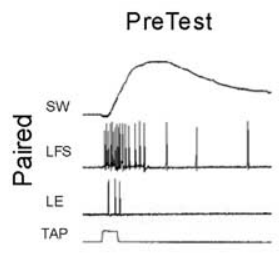

Oxymyoglobin, Abdominal ganglion
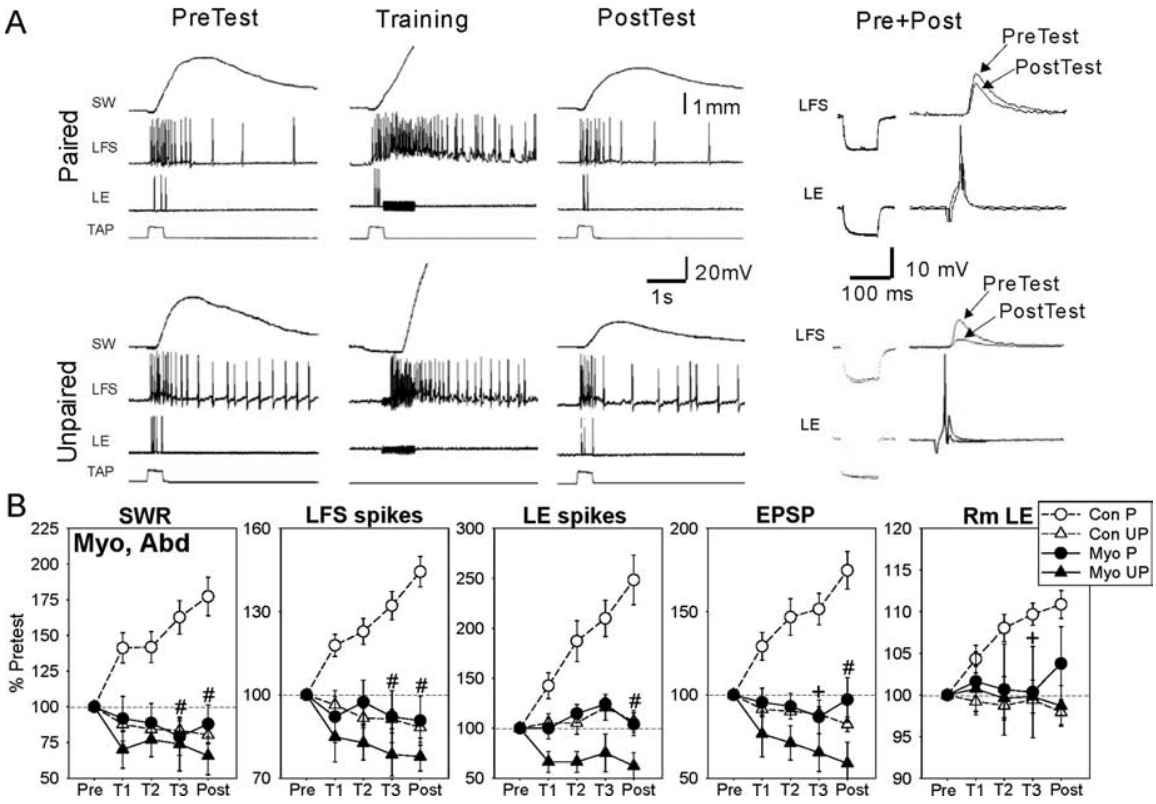

Figure 5. Bathing the abdominal ganglion in a scavenger of NO, oxymyoglobin, blocks conditioning, facilitation of the EPSP, and the changes in sensory neuron membrane properties. $\boldsymbol{A}$, Examples with the abdominal ganglion bathed in oxymyoglobin. $\boldsymbol{B}$ Average results from experiments like the ones shown in $\boldsymbol{A}$ (black symbols; $n=5$ and 5 ) compared with the average control results from Figure 4 (white symbols). SW, Siphon withdrawal; SWR, siphon-withdrawal reflex; Myo, Abd, abdominal ganglion bathed in myoglobin; Rm LE, LE membrane resistance; Con, control; Myo, myoglobin; $P$, paired; UP, unpaired. sensory neurons (Byrne et al., 1974; Hickie et al., 1997). This result demonstrates that the preparations were otherwise healthy and capable of conditioning. However, injecting oxymyoglobin into the LE neuron did reduce the pairing specific increases in evoked LE firing $(F=5.45 ; p<0.05$ for the interaction of drug and pairing on the posttest), the amplitude of the monosynaptic EPSP $(F=5.33 ; p<0.05)$, and the membrane resistance of the LE neuron $(F=5.32 ; p<0.05)$. The effects on evoked LE firing and the monosynaptic EPSP were both abolished when the correlation with LE membrane resistance was taken into account in an analysis of covariance. These results suggest that NO acts directly in the presynaptic sensory neuron to contribute to changes in its membrane properties and that NO contributes to facilitation of the EPSP in part through that process.

\section{Injecting a scavenger of NO into a} motor neuron reduces facilitation Similarly, injecting oxymyoglobin into a single LFS motor neuron (Fig. 7A) did not have a significant effect on siphon withdrawal, presumably because the reflex in this preparation is mediated by two to three LFS motor neurons (Antonov et al., 1999). Injecting oxymyoglobin into the LFS neuron also did not have significant effects on the increases in evoked LE firing or the membrane resistance of the LE neuron, but it did reduce the pairing-specific increase in the amplitude of the monosynaptic EPSP $(F=10.12 ; p<0.01$ for the interaction of drug and pairing on the posttest). Injecting the NO synthase inhibitor $N^{\omega}$-nitro-L-arginine $(10 \mathrm{~mm}$ in the electrode) into a single LFS neuron did not have significant effects on any measure (Fig. $7 B$ ). These results suggest that NO comes from some other source and acts directly in the motor neuron as well as in the sensory neuron to affect facilitation of the EPSP.

Injecting an inhibitor of exocytosis into a motor neuron reduces facilitation One possible postsynaptic action of NO is membrane insertion of AMPA-like glutamate receptors. NO contributes to trafficking and membrane insertion of AMPA receptors during LTP in hippocampus (Huang et al., 2005; Wang et al., 2005). Aplysia sensory-motor neuron EPSPs are thought to be glutamatergic (Dale and Kandel, 1993) and to have both AMPAlike and NMDA-like components (Glanzman, 1994; Conrad et al., 1999; Antonov et al., 2003). Furthermore, insertion of 
AMPA-like glutamate receptors may contribute to heterosynaptic facilitation and homosynaptic potentiation at sensorymotor neuron synapses in vitro (Chitwood et al., 2001; Jin and Hawkins, 2003; Li et al., 2005). To begin to investigate whether glutamate receptor insertion might contribute to the facilitation during conditioning, we injected an LFS motor neuron with the light chain of botulinum toxin type $\mathrm{B}$, which blocks membrane insertion by blocking exocytosis. Injecting botulinum toxin $(0.5 \mathrm{mg} / \mathrm{ml}$ in the electrode $)$ into a single LFS motor neuron (Fig. 8) reduced the pairing-specific increases in evoked LFS firing $(F=7.04 ; p<0.01$ for the interaction of drug and pairing on the posttest) and the amplitude of the monosynaptic EPSP $(F=7.07 ; p<0.01)$, with no significant effects on LE membrane resistance or evoked LE firing. As controls for possible nonspecific actions of botulinum toxin, it had no significant effect on LFS membrane resistance, the pretest responses on any measure, or the response to the US. These results suggest that pairing-specific facilitation of the EPSP during conditioning has a component that depends on postsynaptic exocytosis.

\section{Changes in the EPSP during conditioning are mimicked by presynaptic spike broadening}

To begin to investigate whether the facilitation also involves changes in AMPA-like receptors, we examined changes in the shape of the EPSPs. As in mammals, the sensorimotor neuron EPSP in this preparation has an early component that is selectively blocked by the vertebrate AMPA antagonist CNQX and a later component that is selectively blocked by the vertebrate NMDA antagonist APV (Antonov et al., 2003). Thus, if conditioning involves insertion of AMPA-like glutamate receptors, one would expect that the early part of the EPSP should be enhanced more than the late part. To test that idea, we measured the ratio of the late ( $75 \mathrm{~ms}$ after peak) and early (peak) parts of each EPSP in these experiments (Fig. 9A). Surprisingly, the ratio increased (that is, there was a greater enhancement of the late part of the EPSP) after conditioning $\left(F_{(1,49)}=9.44 ; p<0.01\right.$ on the posttest), and this increase correlated with the increase in the peak amplitude of the EPSP (within-groups correlation in paired experiments, $0.389 ; p<$ $0.05)$.

To attempt to understand the significance of these changes in the late/peak ratio, we examined the effects of drugs with known actions (Fig. 9B). The AMPA receptor antagonist CNQX $(50 \mu \mathrm{M})$ produced an increase in the ratio $\left(F_{(1,16)}=6.12 ; p<0.05\right)$, and

A

A1

\section{Oxymyoglobin, LE sensory neuron}
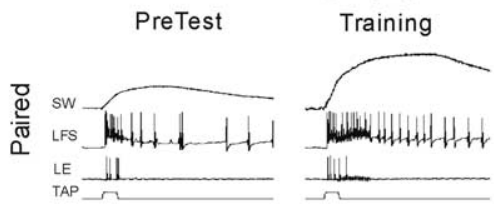

PostTest
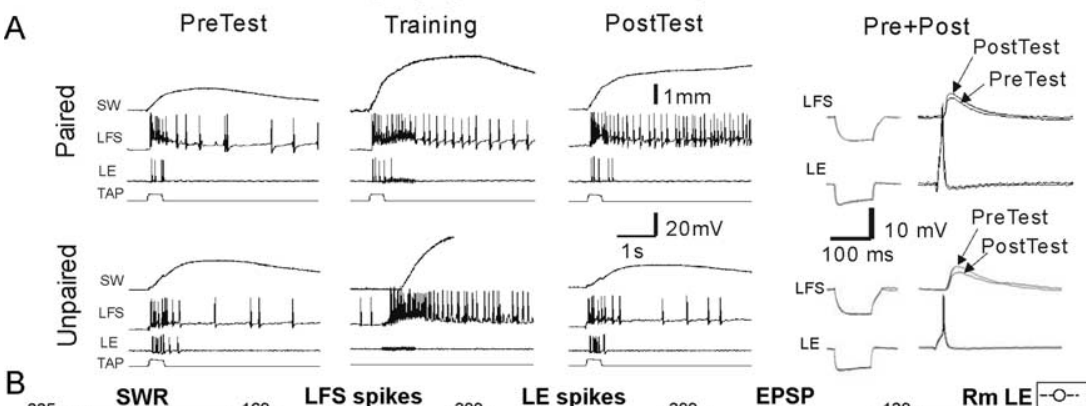

SP

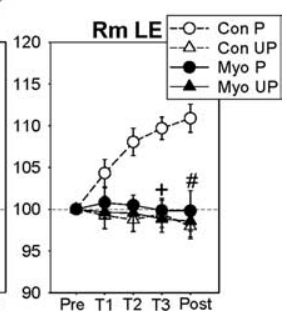

Figure 6. Injecting oxymyoglobin into an LE sensory neuron blocks facilitation and the changes in sensory neuron membrane properties. $\boldsymbol{A}$, Examples after injection of oxymyoglobin into the $L E$ sensory neuron. $\boldsymbol{B}$, Average results from experiments like the ones shown in $\boldsymbol{A}$ ( $n=5$ and 5). SW, Siphon withdrawal; SWR, siphon-withdrawal reflex; Myo, LE, LE neuron injected with myoglobin; Rm LE, LE membrane resistance; Con, control; Myo, myoglobin; $P$, paired; UP, unpaired.

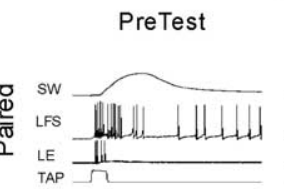

Oxymyoglobin or NOArg, LFS motor neuron
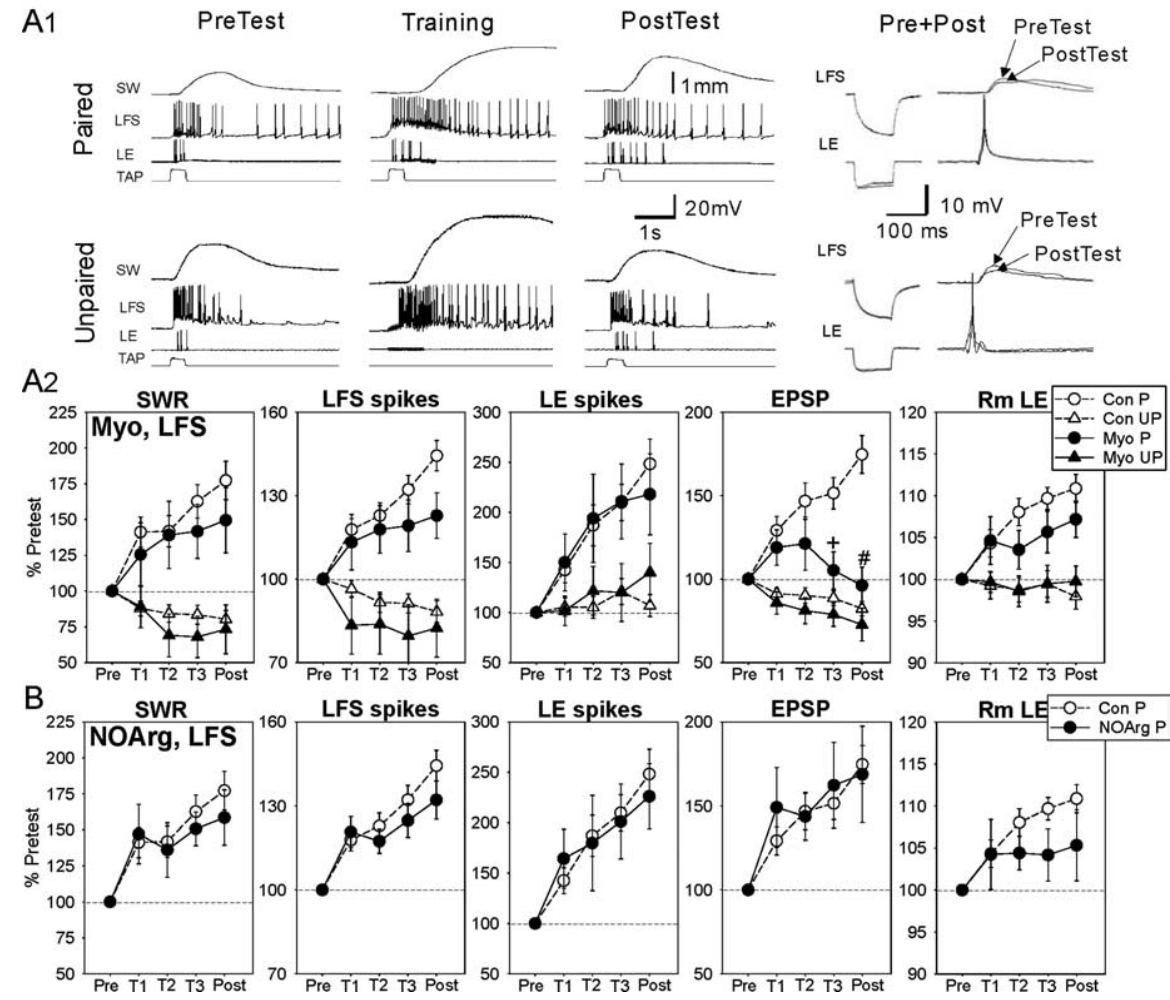

Figure 7. Injecting oxymyoglobin into an LFS motor neuron reduces facilitation, and injecting an inhibitor of NO synthase into the motor neuron has no effect. $\mathbf{A 1}$, Examples afterinjection of oxymyoglobin into the LFS motorneuron. $\mathbf{A 2}$, Average results from experiments like the ones shown in $\boldsymbol{A} \mathbf{1}$ ( $n=5$ and 5). $\boldsymbol{B}$, Average results after injection of $N^{\omega}$-nitro-L-arginine (NOArg) into the LFS neuron $(n=7) . S W$, Siphon withdrawal; SWR, siphon-withdrawal reflex; Myo, LFS, LFS neuron injected with myoglobin; Rm LE, LE membrane resistance; NOArg, LFS, LFS neuron injected with $N^{\omega}{ }^{\omega}$-nitro-L-arginine; Con, control; Myo, myoglobin; $P$, paired; UP, unpaired.

the NMDA receptor antagonist APV $(200 \mu \mathrm{M})$ produced a decrease $(F=5.78 ; p<0.05)$, as expected. The $\mathrm{K}^{+}$channel blocker 4 -AP $(50 \mu \mathrm{M})$, which causes broadening of the presynaptic action potential and thus an in-crease in the peak amplitude of the EPSP 


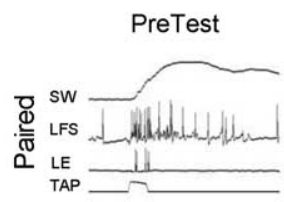

Botulinum toxin, LFS motor neuron
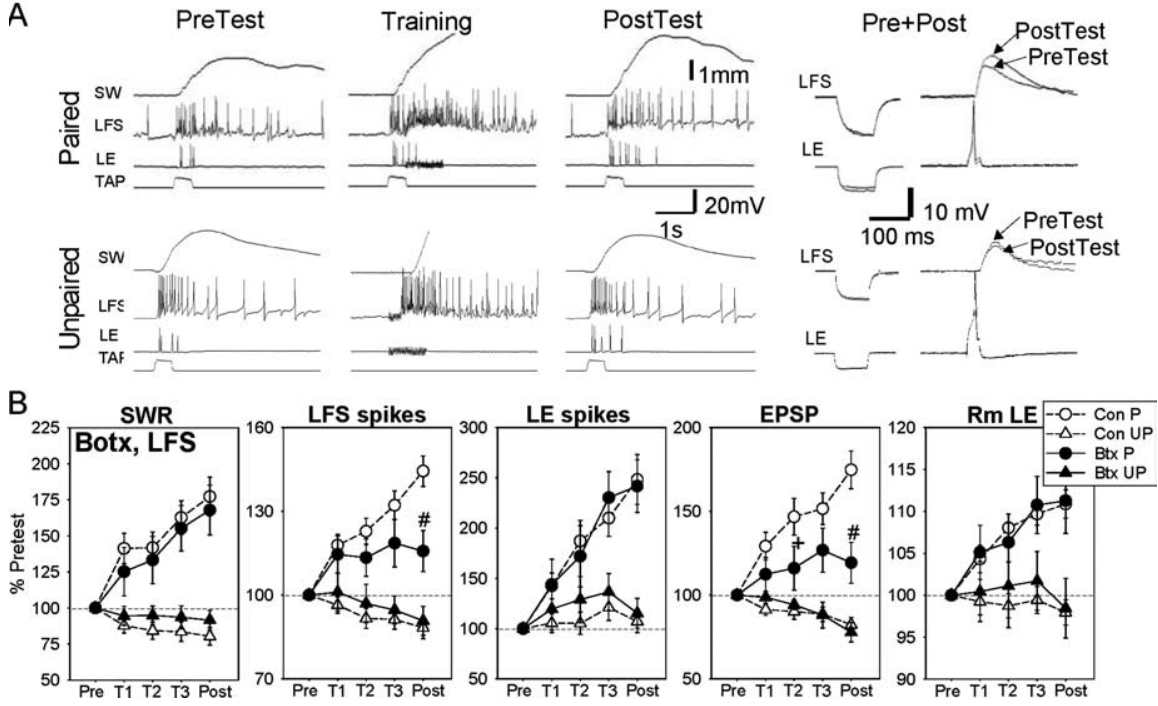

Figure 8. Injecting botulinum toxin into an LFS motor neuron reduces facilitation. $A$, Examples after injection of the light chain of botulinum toxin type $B$ into the LFS motor neuron. $\boldsymbol{B}$, Average results from experiments like the ones shown in $\boldsymbol{A}(n=8$ and 6 ). SW, Siphon withdrawal; SWR, siphon-withdrawal reflex; Botx, LFS, LFS neuron injected with in botulinum toxin; Rm LE, LE membrane resistance; Con, control; $B$ tx, botulinum toxin; $P$, paired; $U P$, unpaired.

(Sugita et al., 1997), also produced an increase in the late/peak ratio $(F=15.98 ; p<0.01)$. Furthermore, there were significant within-groups correlations between broadening of the presynaptic action potential (represented by the size of the symbols for the 4-AP experiments in Fig. 9B3) and the increases in both peak amplitude of the EPSP $(r=0.798 ; p<0.05)$ and the late/peak ratio $(r=0.853 ; p<0.01)$, suggesting that action potential broadening contributes to both effects. Collectively, these results suggest that changes in the shape of the EPSP during conditioning may be attributable to broadening of presynaptic action potentials rather than insertion of postsynaptic glutamate receptors.

\section{Discussion}

\section{Identified L29 facilitatory interneurons express NOS}

The L29 facilitatory interneurons are thought to play important roles in plasticity during conditioning and other types of learning (Hawkins et al., 1981b; Frost et al., 1988; Hawkins, 1989b; Fischer and Carew, 1993, 1995; Fischer et al., 1997). L29 refers to a group of approximately five electrically coupled neurons in the abdominal ganglion that are excited by the CS and US used in conditioning experiments (Hawkins et al., 1981a; Hawkins and Schacher, 1989). Intracellular stimulation of a single L29 neuron produces facilitation of the monosynaptic EPSP from a sensory neuron to a motor neuron and broadening of action potentials in the sensory neuron in either the nervous system (Hawkins, 1981; Hawkins et al., 1981b) or isolated cell culture (Hawkins and Schacher, 1989). Serotonin also contributes to facilitation during conditioning (Mackey et al., 1989; Clark et al., 1994; Eliot et al., 1994; Bao et al., 1998), and the L29 neurons were originally thought to be serotonergic (Bailey et al., 1981). However, several types of evidence indicate that they are not (Hawkins, 1989a; Hawkins and Schacher, 1989), and their facilitatory transmitter has remained unknown. We found that L29 neurons express NOS and that NO plays an important role in facilitation at sensorimotor neuron synapses during conditioning. These results suggest that NO may be one of the previously unidentified facilitatory transmitters of the L29 neurons.

A surprising result of our in situ hybridization experiments is that only two to three of the approximately five L29s express NOS, and the others do not have a detectable level of NOS transcripts. Previous studies had not given any indication that the L29s are functionally heterogenous, although they have somewhat different receptive fields (Hawkins and Schacher, 1989). It is possible that only the NOS-positive L29s are facilitatory interneurons, and stimulation of the others might produce facilitation indirectly through their electrical coupling (Fig. 2B). Alternatively, the NOS-negative L29s might release another facilitatory transmitter, or they might have a much lower level of NOS expression or express a different NOS isoform. However, we have not seen any labeling in the area of the L29, LE, and LFS neurons for other NOS-related isoforms from Aplysia, making that possibility seem unlikely.

\section{Role of NO in the LE membrane property-dependent process of facilitation}

Previous experiments (Hawkins et al., 1983; Clark et al., 1994; Eliot et al., 1994; Bao et al., 1998; Antonov et al., 2003; Roberts and Glanzman, 2003) suggested that facilitation of sensory-motor neuron EPSPs during conditioning involves at least two distinguishable processes: one that is associated with changes in the membrane properties of the LE sensory neurons, including spike broadening, and one or more processes that are independent of those changes. Injection of a peptide inhibitor of PKA into an LE sensory neuron blocks the increases in evoked firing and membrane resistance of the sensory neuron and reduces facilitation of the EPSP during conditioning (Antonov et al., 2003), suggesting that presynaptic PKA mediates the LE membrane property-dependent process. Injection of a scavenger of NO into an LE sensory neuron also blocked the increases in evoked firing and membrane resistance of the LE neuron and facilitation of the EPSP (Fig. 6), suggesting that NO acts directly in the sensory neuron to affect the membrane propertydependent process. However, although application of the NO donor DEA/NO produced facilitation of the EPSP, it had no effect on LE membrane properties (Fig. 3A). Collectively, these results suggest that presynaptic effects of $\mathrm{NO}$ are necessary but not sufficient to produce the LE membrane property-dependent process of facilitation, whereas presynaptic PKA is thought to be both necessary and sufficient (Byrne and Kandel, 1996). One idea that could integrate these findings is that NO may "gate" or enhance activation of PKA by the 5-HT-cAMP pathway. Consistent with that idea, NO and cAMP act synergistically to activate PKA during presynaptic facilitation at lizard neuromuscular junction (Graves et al., 2004). NO similarly enhances activation of PKA in dorsal root ganglion neurites, in which it is thought to act through cGMP to inhibit phosphodiesterase III, which degrades cAMP (Tsukada et al., 2002). However, it is not clear whether NO might act through cGMP in LE sensory neurons. Although physiological evidence suggests that cGMP is present in VC sensory neurons in the pleural ganglia (Lewin and Walters, 1999; Sung et al., 2004), there is no detectable staining for guanylyl cyclase (Martasek et al., 2004) (L. Moroz and M. Bodnarova, 
unpublished observations) or cGMP (Koh and Jacklet, 2001) in the region of the LE neurons.

The increases in evoked firing and membrane resistance of the LE sensory neuron and facilitation of the EPSP were also almost completely blocked by injection of BAPTA into the LFS motor neuron (Antonov et al., 2003), suggesting that the LE membrane property-dependent process involves postsynaptic $\mathrm{Ca}^{2+}$ and retrograde signaling as well as presynaptic PKA. However, injection of a scavenger of NO or an inhibitor of NO synthase into an LFS motor neuron had no significant effect on the increases in evoked firing and membrane resistance of the sensory neuron (Fig. 7), suggesting that NO does not come from the LFS motor neuron and thus is not the putative retrograde messenger for those presynaptic effects. Because the presynaptic effects are blocked by an extracellular scavenger (Fig. 5), NO presumably also does not come from the LE sensory neurons themselves. Single-cell reverse transcription-PCR has revealed an $\mathrm{NO}$ synthase-like transcript in VC sensory neurons from the pleural ganglia, but only after $16 \mathrm{~h}$ in isolated cell culture and not earlier and at very low abundance (Sung et al., 2004). Furthermore, NADPHdiaphorase staining and in situ hybridization did not reveal NO synthase in either the LFS motor neurons or the LE or VC sensory neurons under our conditions (Moroz, 2006) (Figs. 1, 2). Thus, NO presumably comes from some third source, such as the L29 interneurons, and acts as a paracrine rather than a retrograde messenger during conditioning.

\section{Role of NO in the LE membrane property-independent process of facilitation}

The LE membrane property-independent process of facilitation was originally thought to be attributable to presynaptic vesicle mobilization (Gingrich and Byrne, 1985), but it might also involve other mechanisms such as changes in postsynaptic receptors (Chitwood et al., 2001; Li et al., 2005) or synaptic growth. The NO donor DEA/NO produced facilitation that was not associated with any change in LE membrane properties, and NO donors similarly produce presynaptic facilitation or inhibition at other Aplysia synapses without affecting presynaptic membrane properties (Mothet et al., 1996a,b). These results suggest that the LE membrane property-independent process involves NO. Facilitation by DEA/NO was blocked by presynaptic injection of an NO scavenger (Fig. $3 A$ ), and almost all of the facilitation during conditioning (both LE membrane property dependent and independent) was also blocked by presynaptic injection of the scavenger (Fig. 6). However, postsynaptic injection of the scavenger also partially blocked facilitation of the EPSP without having any significant effect on the increases in evoked firing and membrane resistance of the LE neuron (Fig. 7). These results suggest that the
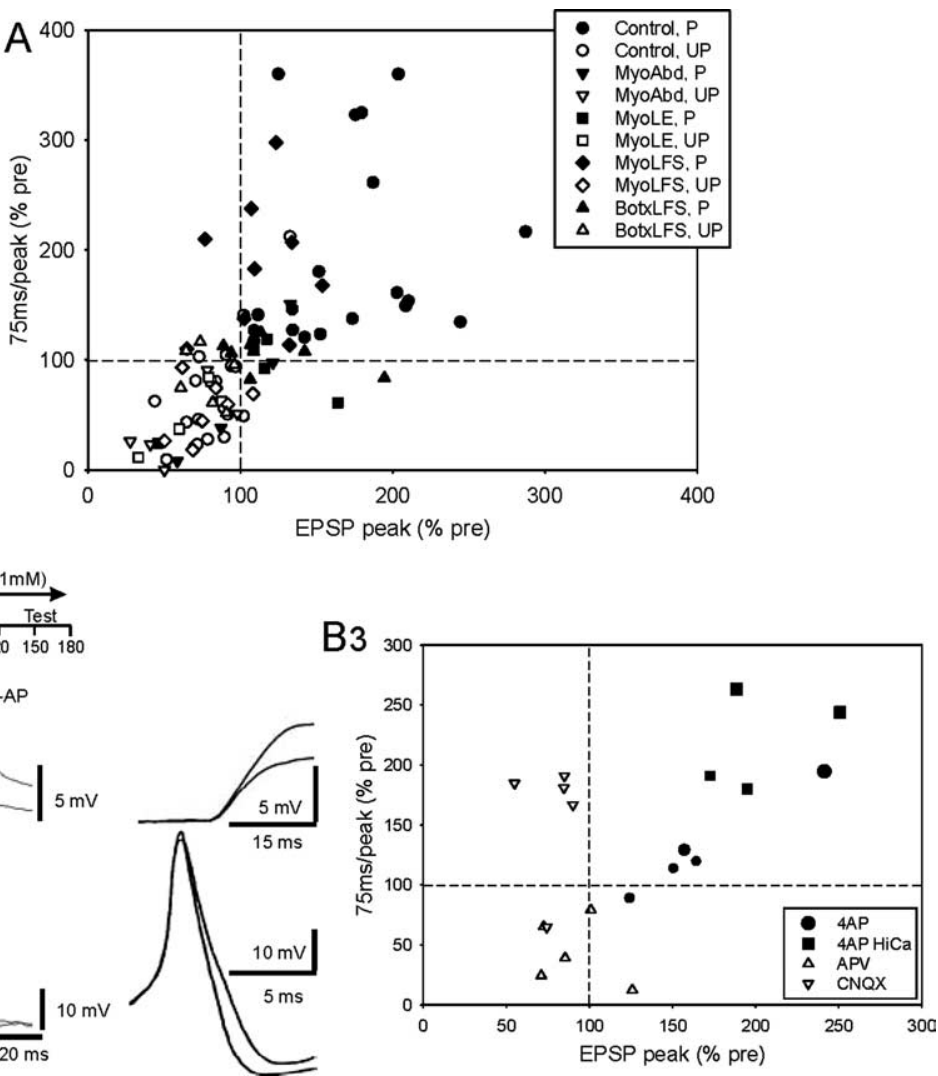

Figure 9. Changes in the EPSP during conditioning are mimicked by presynaptic spike broadening. $\boldsymbol{A}$, Changes in the peak amplitude of the EPSP and the ratio of the late ( $75 \mathrm{~ms}$ after the peak) and early (peak) parts of the EPSP in each of the experiments shown in Figures $4-8$. The data on the posttest have been normalized to the values on the pretest in each experiment. The overal

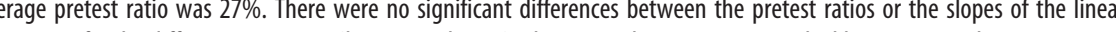
protocol for examining the effects of the drugs on the EPSP. B2, Examples of the action potential in an LE sensory neuron and the 75 me action potential (right). B3, Changes in the peak amplitude of the EPSP and the ratio of the late

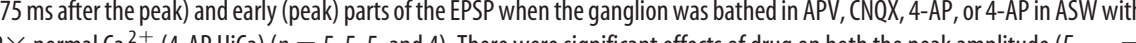
for the ratio. These values were not significantly different in experiments with high $\mathrm{Ca}^{2+}$. For the 4-AP experiments, the size of the symbols is proportional to the amount of broadening of the presynaptic action potential measured from the peak to $10 \%$ of peak on the falling phase. P, Paired; UP, unpaired; Myo, myoglobin; Abd, abdominal ganglion; Botx, botulinum toxin.

LE membrane property-independent process involves both presynaptic and postsynaptic effects of NO that are more than additive and therefore may interact in some way. Consistent with that idea, additional results (Figs. 8, 9) suggest that NO may not contribute to the LE membrane property-independent process by enhancing postsynaptic AMPA-like receptor insertion but instead may enhance postsynaptic exocytosis of a retrograde messenger that affects presynaptic plasticity (Jin and Hawkins, 2003).

Perhaps a simpler alternative, however, is that NO may contribute to the structural modification of existing synapses or the growth of new synapses, which by its nature requires both presynaptic and postsynaptic changes coordinated by extracellular signaling (Cohen-Cory, 2002). The conditioning experiments take $>2 \mathrm{~h}$, which is in the time range of some of the presynaptic and postsynaptic structural modifications that occur during various forms of synaptic plasticity in Aplysia (Glanzman et al., 1990; Jin et al., 2003; Kim et al., 2003; Li et al., 2004) and also in hippocampus (Bozdagi et al., 2000; Luscher et al., 2000; Antonova et al., 2001; Colicos et al., 2001; Nikonenko et al., 2003; Matsuzaki et 
al., 2004). NO is thought to play an important role during synapse formation in a number of systems (Truman et al., 1996; Cramer et al., 1998; Schwarte and Godfrey, 2004; Sunico et al., 2005; Zhang et al., 2005) and is required for the rapid formation of new presynaptic processes (Nikonenko et al., 2003) and clusters of both presynaptic and postsynaptic proteins (Wang et al., 2005) during long-lasting potentiation in hippocampal neurons. In preliminary experiments, we observed a similar increase in clusters of presynaptic proteins during conditioning in the siphon-withdrawal preparation (I. Antonov, I. Antonova, and R. D. Hawkins, unpublished observations). Our present results suggest that NO could play a role in that effect or other structural changes that may accompany facilitation of the EPSP during conditioning in Aplysia.

\section{References}

Abrams TW, Yovell Y, Onyike CU, Cohen JE, Jarrard HE (1998) Analysis of sequence-dependent interactions between calcium and transmitter stimuli in activating adenylyl cyclase in Aplysia: possible contributions to CS-US sequence requirement during conditioning. Learn Mem 4:496-509.

Antonov I, Kandel ER, Hawkins RD (1999) The contribution of facilitation of monosynaptic PSPs to dishabituation and sensitization of the Aplysia siphon withdrawal reflex. J Neurosci 19:10438-10450.

Antonov I, Antonova I, Kandel ER, Hawkins RD (2001) The contribution of activity-dependent synaptic plasticity to classical conditioning in Aplysia. J Neurosci 21:6413-6422.

Antonov I, Antonova I, Kandel ER Hawkins RD (2003) Activity-dependent presynaptic facilitation and Hebbian LTP are both required and interact during classical conditioning in Aplysia. Neuron 37:135-147.

Antonova I, Arancio O, Trillat A-C, Wang H-G, Zablow L, Udo H, Kandel ER, Hawkins RD (2001) Rapid increase in clusters of presynaptic proteins at onset of long-lasting potentiation. Science 294:1547-1550.

Bailey CH, Hawkins RD, Chen MC, Kandel ER (1981) Interneurons involved in mediation and modulation of gill-withdrawal reflex in Aplysia. IV. Morphological basis of presynaptic facilitation. J Neurophysiol 45:340-360.

Bao J-X, Kandel ER, Hawkins RD (1998) Involvement of presynaptic and postsynaptic mechanisms in a cellular analog of classical conditioning at Aplysia sensory-motor neuron synapses in isolated cell culture. J Neurosci 18:458-466.

Bodnarova M, Jezzini S, Weiss KR, Vilim SF, Moroz LL (2002) The distribution of nitric oxide synthase (NOS) in the CNS and peripheral tissues of Aplysia californica. Soc Neurosci Abstr 28:335.5.

Bodnarova M, Martasek P, Moroz LL (2005) Calcium/calmodulindependent nitric oxide synthase activity in the CNS of Aplysia californica: biochemical characterization and link to cGMP pathways. J Inorg Biochem 99:922-928.

Bozdagi O, Shan W, Tanaka H, Benson DL, Huntley GW (2000) Increasing numbers of synaptic puncta during late-phase LTP: N-cadherin is synthesized, recruited to synaptic sites, and required for potentiation. Neuron 28:245-259.

Byrne JH, Kandel ER (1996) Presynaptic facilitation revisited: state and time dependence. J Neurosci 16:425-435.

Byrne JH, Castellucci V, Kandel ER (1974) Receptive fields and response properties of mechanoreceptor neurons innervating skin and mantle shelf of Aplysia. J Neurophysiol 37:1041-1064.

Chitwood RA, Li Q, Glanzman DL (2001) Serotonin facilitates AMPA-type responses in isolated siphon motor neurons of Aplysia in culture. J Physiol (Lond) 534:501-510.

Clark GA, Hawkins RD, Kandel ER (1994) Activity-dependent enhancement of presynaptic facilitation provides a cellular mechanism for the temporal specificity of classical conditioning in Aplysia. Learn Mem 1:243-257.

Cohen-Cory S (2002) The developing synapse: construction and modulation of synaptic structures and circuits. Science 298:770-776.

Colicos MA, Collins BE, Sailor MJ, Goda Y (2001) Remodeling of synaptic actin induced by photoconductive stimulation. Cell 107:605-616.

Conrad P, Wu F, Schacher S (1999) Changes in functional glutamate recep- tors on a postsynaptic neuron accompany formation and maturation of an identified synapse. J Neurobiol 39:237-248.

Cramer KS, Leamey CA, Sur M (1998) Nitric oxide as a signaling molecule in visual system development. Prog Brain Res 118:101-114.

Dale N, Kandel ER (1993) L-Glutamate may be the fast excitatory transmitter of Aplysia sensory neurons. Proc Natl Acad Sci USA 90:7163-7167.

Eliot LS, Hawkins RD, Kandel ER, Schacher S (1994) Pairing-specific, activity-dependent presynaptic facilitation at Aplysia sensory-motor neuron synapses in isolated cell cultures. J Neurosci 14:368-383.

Fischer TM, Carew TJ (1993) Activity-dependent potentiation of recurrent inhibition: a mechanism for dynamic gain control in the siphon withdrawal reflex of Aplysia. J Neurosci 13:1302-1314.

Fischer TM, Carew TJ (1995) Cutaneous activation of the inhibitory L30 interneurons provides a mechanism for regulating adaptive gain control in the siphon withdrawal reflex of Aplysia. J Neurosci 15:762-773.

Fischer TM, Blazis DE, Priver NA, Carew TJ (1997) Metaplasticity at identified inhibitory synapses in Aplysia. Nature 389:860-965.

Frost WN, Kandel ER (1995) Structure of the network mediating siphonelicited siphon withdrawal in Aplysia. J Neurophysiol 73:2413-2427.

Frost WN, Clark GA, Kandel ER (1988) Parallel processing of short-term memory for sensitization in Aplysia. J Neurobiol 19:297-334.

Gingrich KJ, Byrne JH (1985) Simulation of synaptic depression, posttetanic potentiation, and presynaptic facilitation of synaptic potentials from sensory neurons mediating gill-withdrawal reflex in Aplysia. J Neurophysiol 53:652-669.

Glanzman DL (1994) Postsynaptic regulation of the development and longterm plasticity of Aplysia sensorimotor synapses in cell culture. J Neurobiol 25:666-693.

Glanzman DL, Kandel ER, Schacher S (1990) Target-dependent structural changes accompanying long-term synaptic facilitation in Aplysia neurons. Science 249:799-802.

Graves AR, Lewin KA, Lindgren C (2004) Nitric oxide, cAMP and the biphasic muscarinic modulation of ACh release at the lizard neuromuscular junction. J Physiol (Lond) 59:423-432.

Hawkins RD (1981) Interneurons involved in mediation and modulation of gill-withdrawal reflex in Aplysia. III. Identified facilitating neurons increase $\mathrm{Ca}^{2+}$ current in sensory neurons. J Neurophysiol 45:327-339.

Hawkins RD (1989a) Localization of potential serotonergic facilitator neurons in Aplysia by glyoxylic acid histofluorescence combined with retrograde fluorescent labeling. J Neurosci 9:4214-4226.

Hawkins RD (1989b) A biologically based computational model for several simple forms of learning. Psychol Learn Motiv 23:65-108.

Hawkins RD (1996) NO Honey, I don't remember. Neuron 16:465-467.

Hawkins RD (2007) Trans-synaptic signaling by NO during learningrelated synaptic plasticity. In: Learning and memory-a comprehensive reference (Byrne JH, ed). Oxford: Elsevier.

Hawkins RD, Schacher S (1989) Identified facilitator neurons L29 and L28 are excited by cutaneous stimuli used in dishabituation, sensitization, and classical conditioning in Aplysia. J Neurosci 9:4236-4245.

Hawkins RD, Castellucci VF, Kandel ER (1981a) Interneurons involved in mediation and modulation of gill-withdrawal reflex in Aplysia. I. Identification and characterization. J Neurophysiol 45:304-314.

Hawkins RD, Castellucci VF, Kandel ER (1981b) Interneurons involved in mediation and modulation of gill-withdrawal reflex in Aplysia. II. Identified neurons produce heterosynaptic facilitation contributing to behavioral sensitization. J Neurophysiol 45:315-326.

Hawkins RD, Abrams TW, Carew TJ, Kandel ER (1983) A cellular mechanism of classical conditioning in Aplysia: activity-dependent amplification of presynaptic facilitation. Science 219:400-415.

Hawkins RD, Son H, Arancio O (1998) Nitric oxide as a retrograde messenger during long-term potentiation in hippocampus. Prog Brain Res 118:155-172.

Hickie C, Cohen LB, Balaban PM (1997) The synapse between LE sensory neurons and gill motoneurons makes only a small contribution to the Aplysia gill-withdrawal reflex. Eur J Neurosci 9:627-636.

Huang Y, Man HY, Sekine-Aizawa Y, Han Y, Juluri J, Luo H, Cheah J, Lowenstein C, Huganir RL, Snyder SH (2005) S-nitrosylation of $\mathrm{N}$-ethylmaleimide sensitive factor mediates surface expression of AMPA receptors. Neuron 46:533-540.

Jezzini SH, Bodnarova M, Moroz LL (2005) Two-color in situ hybridization in the CNS of Aplysia californica. J Neurosci Methods 149:15-25.

Jin I, Hawkins RD (2003) Presynaptic and postsynaptic mechanisms of a 
novel form of homosynaptic potentiation at Aplysia sensory-motor neuron synapses. J Neurosci 23:7288-7297.

Jin I, Udo H, Kandel ER, Hawkins RD (2003) Rapid increase in synaptophysin puncta at onset of homosynaptic potentiation in Aplysia. Soc Neurosci Abstr 29:291.22.

Kandel ER, Abrams T, Bernier L, Carew TJ, Hawkins RD, Schwartz JH (1983) Classical conditioning and sensitization share aspects of the same molecular cascade in Aplysia. Cold Spring Harbor Symp Quant Biol 48:821-830.

Katzoff A, Ben-Gedalya T, Susswein AJ (2002) Nitric oxide is necessary for multiple memory processes after learning that food is inedible in Aplysia. J Neurosci 22:9581-9594.

Kim J-H, Udo H, Li H-L, Toun TY, Chen M, Kandel ER, Bailey CH (2003) Presynaptic activation of silent synapses and growth of new synapses contribute to intermediate and long-term facilitation in Aplysia. Neuron 40:151-165.

Koh HY, Jacklet JW (1999) Nitric oxide stimulates cGMP production and mimics synaptic responses in metacerebral neurons of Aplysia. J Neurosci 19:3818-3826.

Koh HY, Jacklet JW (2001) Nitric oxide induces cGMP immunoreactivity and modulates membrane conductance in identified central neurons of Aplysia. Eur J Neurosci 13:553-560.

Lev-Ram V, Makings LR, Keitz PF, Kao JP, Tsien RY (1995) Long-term depression in cerebellar Purkinje neurons results from coincidence of nitric oxide and depolarization-induced $\mathrm{Ca}^{2+}$ transients. Neuron 15:407-415.

Lewin MR, Walters ET (1999) Cyclic GMP pathway is critical for inducing long-term sensitization of nociceptive sensory neurons. Nat Neurosci 2:18-23.

Li H, Huang BSH, Kandel ER (2004) Innervation-dependent clustering of glutamate receptors during regeneration and plasticity-associated synaptogenesis in Aplysia. Soc Neurosci Abstr 30:614.18.

Li Q, Roberts AC, Glanzman DL (2005) Synaptic facilitation and behavioral dishabituation in Aplysia: dependence on release of $\mathrm{Ca}^{2+}$ from postsynaptic intracellular stores, postsynaptic exocytosis, and modulation of postsynaptic AMPA receptor efficacy. J Neurosci 25:5623-5637.

Lin XY, Glanzman DL (1994a) Hebbian induction of long-term potentiation of Aplysia sensorimotor synapses: partial requirement for activation of a NMDA-related receptor. Proc R Soc Lond B Biol Sci 255:215-221.

Lin XY, Glanzman DL (1994b) Long-term potentiation of Aplysia sensorimotor synapses in cell culture: regulation by postsynaptic voltage. Proc $\mathrm{R}$ Soc Lond B Biol Sci 255:113-118.

Luscher C, Nicoll RA, Malenka RC, Muller D (2000) Synaptic plasticity and dynamic modulation of the postsynaptic membrane. Nat Neurosci 3:545-550.

Mackey SL, Kandel ER, Hawkins RD (1989) Identified serotonergic neurons LCB1 and RCB1 in the cerebral ganglia of Aplysia produce presynaptic facilitation of siphon sensory neurons. J Neurosci 9:4227-4235.

Martasek P, Sadreev RI, Bodnarova M, Uvarov P, Panchin YV, Moroz LL (2002) Two neuronal-like nitric oxide synthases in Aplysia californica: cloning and characterization. Soc Neurosci Abstr 28:335.6.

Martasek P, Bodnarova M, Panchin YV, Sadreyev RI, Uvarov PN, Jezzini SH, Moroz LL (2004) Characterization of NO/cGMP signaling in the CNS of Aplysia californica. Soc Neurosci Abstr 30:497.10.

Matsuzaki M, Honkura N, Ellis-Davies GCR, Kasai H (2004) Structural basis of long-term potentiation in single dendritic spines. Nature 429:761-766.

Moroz LL (2000) Giant identified NO-releasing neurons and comparative histochemistry of putative nitrergic systems in gastropod molluscs. Microsc Res Tech 49:557-569.

Moroz LL (2006) Localization of putative nitrergic neurons in peripheral chemosensory areas and the central nervous system of Aplysia californica. J Comp Neurol 495:10-20.

Moroz LL, Kohn AB (2007) On the comparative biology of NO synthetic pathways: parallel evolution of NO mediated signaling. In: Nitric oxide, advances in experimental biology (Trimmer B, Tota B, Wang T, eds), pp 1-45. Amsterdam: Elsevier.
Moroz LL, Chen D, Gillette MU, Gillette R (1996) Nitric oxide synthase activity in the molluscan CNS. J Neurochem 66:873-876.

Moroz LL, Dahlgren RL, Boudko D, Sweedler JV, Lovell P (2005) Direct single cell determination of nitric oxide synthase related metabolites in identified nitrergic neurons. J Inorg Biochem 99:929-939.

Moroz LL, Edwards JR, Puthanveettil SV, Kohn AB, Ha T, Heyland A, Knudsen B, Sahni A, Yu F, Liu L, Jezzini S, Lovell P, Iannucculli W, Chen M, Nguyen T, Sheng H, Shaw R, Kalachikov S, Panchin YV, Farmerie W, et al. (2006) Neuronal transcriptome of Aplysia: neuronal compartments and circuitry. Cell 127:1453-1467.

Mothet JP, Fossier P, Tauc L, Baux G (1996a) Opposite actions of nitric oxide on cholinergic synapses: which pathways. Proc Natl Acad Sci USA 93:8721-8726.

Mothet JP, Fossier P, Tauc L, Baux G (1996b) NO decreases evoked quantal Ach release at a synapse of Aplysia by a mechanism independent of $\mathrm{Ca}^{2+}$ influx and protein kinase G. J Physiol (Lond) 493:769-784.

Murphy GG, Glanzman DL (1996) Enhancement of sensorimotor connections by conditioning-related stimulation in Aplysia depends on postsynaptic $\mathrm{Ca}^{2+}$. Proc Natl Acad Sci USA 93:9931-9936.

Murphy GG, Glanzman DL (1997) Mediation of classical conditioning in Aplysia californica by long-term potentiation of sensorimotor synapses. Science 278:467-471.

Murphy GG, Glanzman DL (1999) Cellular analog of differential classical conditioning in Aplysia: disruption by the NMDA receptor antagonist DL-2-amino-5-phosphono-valerate. J Neurosci 19:10595-10602.

Nikonenko I, Jourdain P, Muller D (2003) Presynaptic remodeling contributes to activity-dependent synaptogenesis. J Neurosci 24:8498-8505.

Ocorr KA, Walters ET, Byrne JH (1985) Associative conditioning analog selectively increases cAMP levels of tail sensory neurons in Aplysia. Proc Natl Acad Sci USA 82:2548-2552.

Roberts AC, Glanzman DL (2003) Learning in Aplysia: looking at synaptic plasticity from both sides. Trends Neurosci 26:662-670.

Sadreyev RI, Panchin Y, Uvarov P, Belyavski A, Matz M, Moroz LL (2000) Cloning of nitric oxide synthase (NOS) from Aplysia californica. Soc Neurosci Abstr 26:343.16.

Schwarte RC, Godfrey EW (2004) Nitric oxide synthase activity is required for postsynaptic differentiation of the embryonic neuromuscular junction. Dev Biol 273:276-284.

Sugita S, Baxter DA, Byrne JH (1997) Differential effects of 4 -aminopyridine, serotonin, and phorbol esters on facilitation of sensorimotor connections in Aplysia. J Neurophysiol 77:177-185.

Sung Y-J, Walters ET, Ambron RT (2004) A neuronal isoform of protein kinase $\mathrm{G}$ couples mitogen-activated protein kinase nuclear import to axotomy-induced long-term hyperexcitability in Aplysia sensory neurons. J Neurosci 24:7583-7595.

Sunico CR, Portillo F, Gonzalez-Forero D, Moreno-Lopez B (2005) Nitricoxide-directed synaptic remodeling in the adult mammalian CNS. J Neurosci 25:1448-1458.

Truman JW, de Vente J, Ball EE (1996) Nitric oxide-sensitive guanylate cyclase activity is associated with the maturational phase of neuronal development in insects. Development 122:3949-3958.

Tsukada S, Keino-Masu K, Masu M, Fukada J (2002) Activation of protein kinase A by nitric oxide in cultured dorsal root ganglion neurites of the rat, examined by a fluorescence probe, ARII. Neurosci Lett 318:17-20.

Walters ET, Byrne JH (1983) Associative conditioning of single sensory neurons suggests a cellular mechanism for learning. Science 219:405-408.

Wang H-G, Lu F-M, Jin I, Udo H, Kandel ER, de Vente J, Walter U, Lohmann SM, Hawkins RD, Antonova I (2005) Presynaptic and postsynaptic roles of NO, cGK, and RhoA in long-lasting potentiation and aggregation of synaptic proteins. Neuron 45:389-403.

Winer BJ, Brown DR, Kenneth MM (1991) Statistical principles in experimental design. New York: McGraw-Hill.

Zhang N, Beuve A, Townes-Anderson E (2005) The nitric oxide-cGMP signaling pathway differentially regulates presynaptic structural plasticity in cone and rod cells. J Neurosci 25:2761-2770. 